\title{
A Convenient Route to 2-Bromo-3-chloronorbornadiene and 2,3-Dibromonorbornadiene
}

\author{
Anders Lennartson \\ Maria Quant \\ Kasper Moth-Poulsen*
}

Department of Chemistry and Chemical Engineering, Chalmers University of Technology, 41296 Gothenburg, Sweden

Kasper.moth-poulsen@chalmers.se

This paper is dedicated to Prof. K. P. C. Vollhardt on the occasion of his $69^{\text {th }}$ birthday. Thank you for inspirational leadership and enlightening supervision.

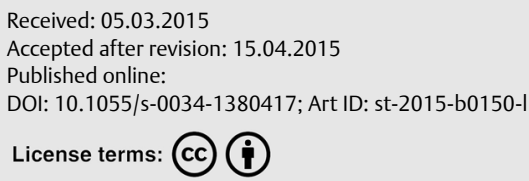

Abstract Substituted norbornadienes are useful in a wide range of applications, including molecular solar-thermal (MOST) energy storage systems. An important precursor for 2,3-substituted norbornadienes is 2-bromo-3-chloronorbornadiene, where the two halogen atoms can be substituted selectively through two consecutive Suzuki cross-coupling reactions. Previous routes to 2 -bromo-3-chloronorbornadiene have used 1,2-dibromoethane as a brominating agent, a substance known to be carcinogenic and the use of which is restricted in certain countries. Herein is reported a one-pot route to 2-bromo-3-chloronorbornadiene in $50 \%$ yield using p-toluenesulfonyl bromide as a bromine source. In addition, the procedure has been adapted to allow synthesis of 2,3-dibromonorbornadiene in $37 \%$ yield.

Key words bromine, chlorine, organometallic reagents, regioselectivity, alkenes

Norbornadiene (1) was first obtained through a DielsAlder reaction between cyclopentadiene and acetylene and reported in a patent from $1951 .{ }^{1}$ It was soon found that norbornadiene and its derivatives undergo a photoinduced intramolecular [2+2] cycloaddition to yield its valence isomer quadricyclane $(\mathbf{2}$, Scheme 1$){ }^{2}$ This reaction is reversible, and since $\mathbf{2}$ is a strained molecule this reaction can be used to store solar energy.

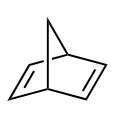

1
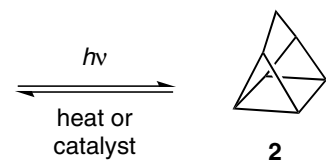

2
Scheme 1 Reversible isomerization of 1

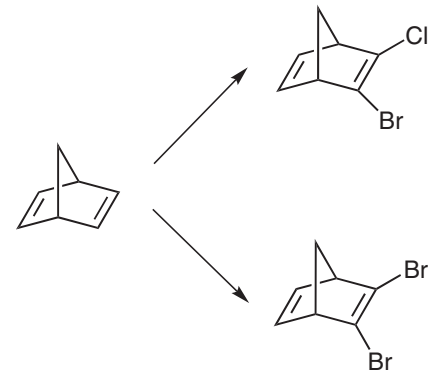

This approach to store solar energy has recently been referred to as molecular solar-thermal (MOST) energy storage, $^{3}$ and studies of norbornadienes as potential MOST systems have been reviewed. ${ }^{4}$ Not only are norbornadienes interesting for energy storage, but norbornadienes have found a wide range of other applications in science. ${ }^{5}$ We have a special interest ${ }^{6}$ in 2 -bromo-3-chloronorbornadiene (3), since the 2- and 3-positions can be selectively substituted through two consecutive Suzuki cross-coupling reactions, one at ambient temperature and one at elevated temperature. ${ }^{7}$ The previously published routes to 2 - and 2,3-dihalogenated norbornadienes are summarized in Scheme $2^{1,8-14}$

Early attempts to deprotonate $\mathbf{1}$ with alkyllithium or alkylsodium failed due to rapid decomposition into sodium cyclopentadienide and sodium acetylenide. ${ }^{15}$ Later, it was found that $\mathbf{1}$ is readily deprotonated by Schlosser's base in THF at low temperature, ${ }^{16}$ and treatment of the metalated norbornadiene with 1,2-dibromoethane or $p$-toluenesulfonyl chloride affords 2-bromonorbornadiene (4), or 2-chloronorbornadiene (5), in $34 \%$ or $40 \%$ yield, respectively. ${ }^{13}$ Synthesis of 2,3-dihalogenated norbornadienes is less straightforward, since 2,3-dimetalated norbornadiene is unstable due to decomposition into metal cyclopentadienide and metal acetylide. Also, 2-bromonorbornadiene undergo fast lithium-bromine exchange when treated with alkyllithium, thus forming 2-lithionorbornadiene rather than 2-bromo-3-lithionorbornadiene, ${ }^{13}$ so the two sites cannot be deprotonated successively. It was found, however, that 2-potassionorbornadiene (6) was a strong enough base to deprotonate 4 to yield 2-bromo-3-potassionorbornadiene (7). Consecutive reaction with 1,2-dibromoethane gives 2,3-dibromonorbornadiene $(\mathbf{8}) .{ }^{13}$ This strategy was further investigated by Tam and co-workers who developed a practically useful route to $8{ }^{14}$ By treating $\mathbf{8}$ with tert-bu- 


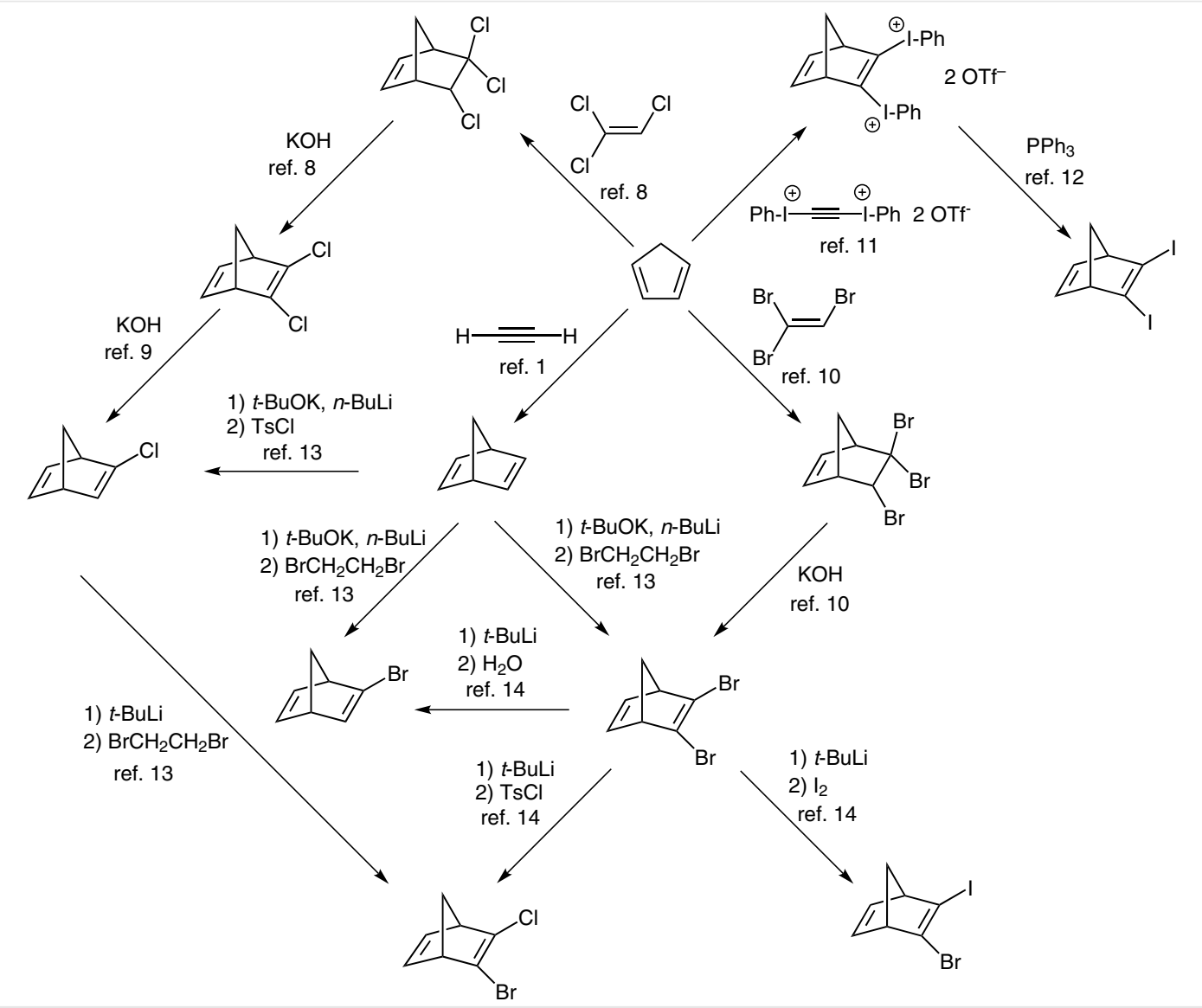

Scheme 2 Synthesis of 2- and 2,3-halogenated norbornadienes ${ }^{1,8-14}$

tyllithium followed by water, $p$-toluenesulfonyl chloride, or iodine, they obtained 4, 3, or 2-bromo-3-iodonorbornadiene in $61 \%, 75 \%$, and $82 \%$ yield, respectively.

The use of 1,2-dibromoethane as a brominating agent is problematic since it has been known for a long time to be carcinogenic, ${ }^{17}$ and its use is restricted in some countries (including Sweden). Although unrestricted in other countries, its use should be strongly discouraged. In this context, it should also be noted that some products obtained by bromination of norbornadiene with bromine have also been reported to be toxic. ${ }^{18}$ Alternative routes to 3 via 5,5,6-halonorbornenes (Scheme 2 ) requires high temperatures and pressures, and we were not able to obtain 3 by these procedures. Thus, we set out to modify the procedure introduced by Tam and co-workers to produce 3 , using an alternative brominating agent and to reduce the long reaction times allowing halonorbornadienes to be conveniently produced during a normal working day.

Since metalated norbornadiene can be conveniently chlorinated by $p$-toluenesulfonyl chloride, a logical choice for a replacement of 1,2-dibromethane would be $p$-toluene- sulfonyl bromide, which is easily prepared ${ }^{19}$ from commercially available $p$-toluenesulfonyl hydrazide. ${ }^{20}$ When stored in the dark at $-20^{\circ} \mathrm{C}, p$-toluenesulfonyl bromide was stable for at least one month.

To deprotonate norbornadiene (Scheme 3), n-butyllithium is slowly added to a solution of norbornadiene and potassium tert-butoxide in THF to give a yellow solution of the metalated norbornadiene $\mathbf{6}$ where, for the sake of simplicity, it is assumed that potassium rather than lithium coordinate the deprotonated norbornadiene. Addition of butyllithium should be slow, and an excess of norbornadiene appears to be necessary, since treating norbornadiene with a stoichiometric amount of Schlosser's base did not give a clean metalation. We found that adding 0.5 equivalents of p-toluenesulfonyl bromide to such a solution followed by stirring at $-41{ }^{\circ} \mathrm{C}$ gave a thick brown gel. These conditions are circumvented by using an excess of norbornadiene. Tam and co-workers ${ }^{14}$ used two equivalents (meaning that the maximum conversion of norbornadiene is $25 \%$ in the synthesis of $\mathbf{8}$; we reduced this excess to 1.2 equivalents). 


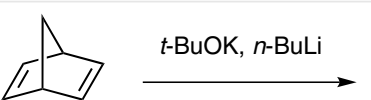

1

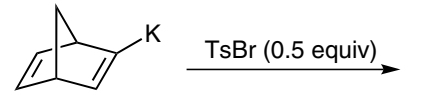

6

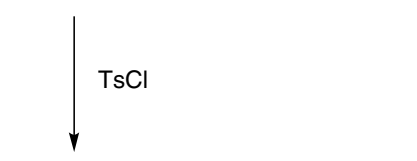

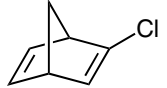
$n$-BuLi $\checkmark$<smiles>ClC1=C(Cl)C2C=CC1C2</smiles><smiles>ClC1=C(Br)C2C=CC1C2</smiles>

3

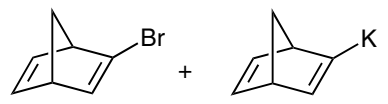

4

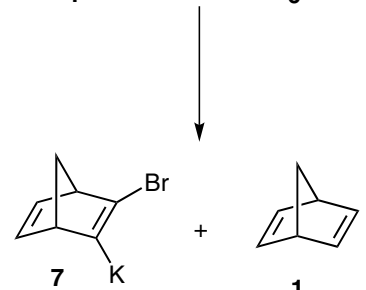

1

$\operatorname{TsBr}(0.5$ equiv $)$

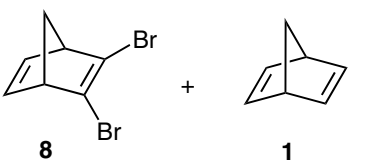

Scheme $\mathbf{3}$ Synthesis of $\mathbf{3}$ and $\mathbf{8}$ from $\mathbf{1}$

To prepare $\mathbf{3}$, the solution of $\mathbf{6}$ is treated with $p$-toluenesulfonyl chloride to give $\mathbf{5}$, which is not isolated. Compound $\mathbf{5}$ can be deprotonated in situ with $n$-butyllithium to give $\mathbf{9}$. On treating the resulting brown suspension with $p$-toluenesulfonyl bromide, the brown color is lost within a few minutes, and $\mathbf{3}$ can be extracted from the reaction mixture. ${ }^{21}$ This allows $\mathbf{3}$ to be produced in a one-pot reaction, rather than first preparing and isolating 8 .

Having found a route to $\mathbf{3}$, we also adapted this procedure to the synthesis of 8: 0.5 equivalents $p$-toluenesulfonyl bromide are added to the solution of $\mathbf{6}$, which gives a brown solution of $\mathbf{6}$ and 4 . At $-41{ }^{\circ} \mathrm{C}$, this mixture gives $\mathbf{7}$ and $\mathbf{1}$ and the color remains dark brown. This deprotonation is apparently incomplete and we, as did Tam and co-workers, obtained $\mathbf{4}$ as a byproduct. When another 0.5 equivalents of $p$-toluenesulfonyl bromide are added, the dark color disappears within a few minutes, and $\mathbf{8}$ is obtained by extraction and distillation. ${ }^{22}$

The yield of $\mathbf{3}$ was $50 \%$, close to the previously reported yield of $49 \%$ over two steps. However, our yield based on $\mathbf{1}$, the most expensive starting material, was $42 \%$, while the previous protocol had a $12 \%$ yield based on 1 . The yield of 2 reported in the literature is 65\%, but obtaining these high yields requires great care, and we typically obtained around
$35 \%$ in our lab, very similar to the $37 \%$ we obtained in this study. The yield based on $\mathbf{1}$ was $15 \%$ compared to $16 \%$ in the previously published procedure. In conclusion, we have reported modified routes to $\mathbf{3}$ and $\mathbf{8}$ avoiding the use of toxic 1,2-dibromoethane and significantly reducing the reaction times.

\section{Acknowledgment}

The authors would like to thank the following funding agencies for financial support: Swedish Research Council (young research grant), Swedish Strategic Research Council (Future Research Leader 5), K. \& A. Wallenberg Foundation (Wallenberg Academy Fellow 2014), Chalmers Materials and Energy Areas of Advance.

\section{References and Notes}

(1) Hyman, I. BE 498176, 1951.

(2) (a) Cristol, S. J.; Snell, R. L. J. Am. Chem. Soc. 1958, 80, 1950. (b) Dauben, W. G.; Cargill, R. L. Tetrahedron 1961, 15, 197. (c) Hammond, G. S.; Turro, N. J.; Fischer, A. J. Am. Chem. Soc. 1961, 83, 4674. (d) Smith, C. D. Org. Synth. 1971, 51, 133.

(3) (a) Moth-Poulsen, K.; Coso, D.; Börjesson, K.; Vinokurov, N.; Meier, S. K.; Majumdar, A.; Vollhardt, K. P. C.; Segalman, R. A. Energy Environ. Sci. 2012, 5, 8534. (b) Börjesson, K.; Lennartson, A.; Moth-Poulsen, K. ACS Sustainable Chem. Eng. 2013, 1, 585. 
(4) (a) Bren, V. A.; Dubonosov, A. D.; Minkin, V. I.; Chernoivanov, V. A. Russ. Chem. Rev. 1991, 60, 451. (b) Dubonosov, A. D.; Bren, V. A.; Chernoivanov, V. A. Russ. Chem. Rev. 2002, 71, 917. (c) Lennartson, A.; Roffey, A.; Moth-Poulsen, K. Tetrahedron Lett. 2015, 56, 1457.

(5) (a) Dalkilic, E.; Guney, M.; Dastan, A.; Saracoglu, N.; De Lucchi, O.; Fabris, F. Tetrahedron Lett. 2009, 50, 1989. (b) Borsato, G.; Linden, A.; De Lucchi, O.; Lucchini, V.; Wolstenholme, D.; Zambon, A. J. Org. Chem. 2007, 72, 4272. (c) Tranmer, G. K.; Tam, W. J. Org. Chem. 2001, 66, 5113. (d) Fan, C.-A.; Ferber, B.; Kagan, H. B.; Lafon, O.; Lesot, P. Tetrahedron Asymmetry 2008, 19, 2666. (e) Wigglesworth, T. J.; Branda, N. R. Adv. Mater. 2004, 16, 123. (f) Monti, H.; Corriol, C.; Bertrand, M. Tetrahedron Lett. 1982, 23, 5539. (g) Hayashi, T.; Ueyama, K.; Tokunaga, N.; Yoshida, K. J. Am. Chem. Soc. 2003, 125, 11508. (h) Mayo, P.; Tam, W. Tetrahedron 2002, 58, 9513.

(6) Gray, V.; Lennartson, A.; Ratanalert, P.; Börjesson, K.; MothPoulsen, K. Chem. Commun. 2014, 50, 5330.

(7) Yoo, W.-J.; Tsui, G. C.; Tam, W. Eur. J. Org. Chem. 2005, 1044.

(8) Schmerling, L. US 1956-580469 2914571, 1959.

(9) Adam, W.; De Lucchi, O.; Pasquato, L.; Will, B. Chem. Ber. 1987, $120,531$.

(10) Schmerling, L. US 1956-580467 2905725, 1959.

(11) Stang, P. J.; Zhdankin, V. V. J. Am. Chem. Soc. 1991, 113, 4571.

(12) Stang, P. J.; Schwarz, A.; Blume, T.; Zhdankin, V. V. Tetrahedron Lett. 1992, 33, 6759.

(13) Kenndoff, J.; Polborn, K.; Szeimies, G. J. Am. Chem. Soc. 1990, $112,6117$.

(14) Tranmer, G. K.; Yip, C.; Handerson, S.; Jordan, R. W.; Tam, W. Can. J. Chem. 2000, 78, 527.

(15) (a) Finnegan, R. A.; McNees, R. S. Tetrahedron Lett. 1962, 755. (b) Wittig, G.; Hahn, E. Angew. Chem. 1960, 72, 781. (c) Streitwieser, A. Jr.; Caldwell, R. A. J. Org. Chem. 1962, 27, 3360. (d) Wittig, G.; Otten, J. Tetrahedron Lett. 1963, 4, 601.

(16) (a) Staehle, M.; Lehmann, R.; Kramar, J.; Schlosser, M. Chimia 1985, 39, 229. (b) Verkruijsse, H. D.; Brandsma, L. Recl. Trav. Chim. Pays-Bas 1986, 105, 66.

(17) (a) Ramsey, J. C.; Park, C. N.; Ott, M. G.; Gehring, P. J. Toxicol. Appl. Pharmacol. 1979, 47, 411. (b) Ott, M. G.; Scharnweber, H. C.; Langner, R. R. Br. J. Ind. Med. 1980, 37, 163.

(18) Winstein, S. J. Am. Chem. Soc. 1961, 83, 1516.

(19) p-Toluenesulfonyl Bromide

p-Toluenesulfonyl hydrazide ( $50 \mathrm{~g}, 0.27 \mathrm{~mol}$ ) was mixed with $\mathrm{CHCl}_{3}(500 \mathrm{~mL})$ at $0{ }^{\circ} \mathrm{C}$. Small amounts of ice were also added to the reaction mixture throughout the reaction. Bromine $(27 \mathrm{~mL}$, $0.54 \mathrm{~mol}$ ) was added in small portions allowing the orange color to disappear between each addition. If, when the last portion of bromine was added, the color was still white, a small amount of extra bromine was added until a light orange colour persisted. The phases were separated and the organic phase was washed with sat. aq $\mathrm{NaHCO}_{3}$ solution $(200 \mathrm{~mL})$ and $1 \%$ aq $\mathrm{Na}_{2} \mathrm{~S}_{2} \mathrm{O}_{3}$ solution $(100 \mathrm{~mL})$. The organic phase was dried over $\mathrm{Na}_{2} \mathrm{SO}_{4}$, filtered, and the solvent was removed on a rotary evaporator. The product was ground to powder and dried at $5 \cdot 10^{-2}$ mbar until NMR showed no traces of solvents or $\mathrm{H}_{2} \mathrm{O}$; yield: $59.6 \mathrm{~g}(94 \%)$.
(20) (a) Litvinenko, L. M.; Dadali, V. A.; Savelova, V. A.; Krichevtsova, T. I. Zh. Obshch. Khim. 1964, 34, 3730. (b) Shcherbakova, I. Science of Synthesis; Vol. 31a; Ramsden, C. A., Ed.; Georg Thieme Verlag: Stuttgart, 2007, 775.

(21) 2-Bromo-3-chloronorbornadiene (3) Potassium tert-butoxide $(11.2 \mathrm{~g}, 0.10 \mathrm{~mol})$ was dissolved in THF $(200 \mathrm{~mL})$, and the solution was cooled to $-84^{\circ} \mathrm{C}$. Norbornadiene $(12.2 \mathrm{~mL}, 0.12 \mathrm{~mol})$ was added, followed by $n$-BuLi $(2.5 \mathrm{M}$ in hexanes, $40 \mathrm{~mL}, 0.10 \mathrm{~mol}$ ) over $60 \mathrm{~min}$. The yellow solution was stirred for $5 \mathrm{~min}$ at $-84^{\circ} \mathrm{C}$ and $60 \mathrm{~min}$ at $-41^{\circ} \mathrm{C}$. The solution was cooled again to $-84^{\circ} \mathrm{C}$, and $p$-toluenesulfonyl chloride (19.0 $\mathrm{g}, 0.10 \mathrm{~mol}$ ) was added. The mixture was stirred for $30 \mathrm{~min}$ and $n$-BuLi (2.5 M in hexanes, $40 \mathrm{~mL}, 0.10 \mathrm{~mol}$ ) was added over 60 min. The mixture was stirred for $5 \mathrm{~min}$ at $-84^{\circ} \mathrm{C}$ and $60 \mathrm{~min}$ at $-41{ }^{\circ} \mathrm{C}$. The solution was cooled to $-84{ }^{\circ} \mathrm{C}$, and $p$-toluenesulfonyl bromide $(23.4 \mathrm{~g}, 0.10 \mathrm{~mol})$ was added. The mixture was stirred for $15 \mathrm{~min}$ and was then heated to ambient temperature on a room-tempered water bath. The reaction mixture was quenched with $\mathrm{H}_{2} \mathrm{O}(50 \mathrm{~mL})$, the phases were separated, and the aqueous phase was extracted with $\mathrm{Et}_{2} \mathrm{O}(3 \times 20 \mathrm{~mL})$. The solvents from the combined organic phases were slowly removed on a rotary evaporator $\left(40^{\circ} \mathrm{C}, 300 \mathrm{mbar}\right)$. The residue was dissolved in pentane $(50 \mathrm{ml})$, washed with $\mathrm{H}_{2} \mathrm{O}(10 \times 10 \mathrm{~mL})$, brine $(20 \mathrm{~mL})$, and dried over $\mathrm{Na}_{2} \mathrm{SO}_{4}$. The solvent was removed in vacuo $\left(40^{\circ} \mathrm{C}, 300 \mathrm{mbar}\right)$ and the product distilled $\left(2 \times 10^{-2}\right.$ mbar) using a short Vigreux column, collecting the main fraction at $25-27^{\circ} \mathrm{C}$. This afforded 3 as a colorless liquid; yield 10.24 $\mathrm{g}(50 \%)$. Analytical data were consistent with previous reports. ${ }^{14}$ The product was stored at $-20^{\circ} \mathrm{C}$ and should be used within a few weeks to avoid decomposition.

(22) 2,3-Dibromonorbornadiene (8)

Potassium tert-butoxide ( $11.2 \mathrm{~g}, 0.10 \mathrm{~mol}$ ) was dissolved in THF $(200 \mathrm{~mL})$, and the solution was cooled to $-84^{\circ} \mathrm{C}$. Norbornadiene $(12.2 \mathrm{~mL}, 0.12 \mathrm{~mol})$ was added followed by $n$-BuLi $(2.5 \mathrm{M}$ in hexanes, $40 \mathrm{~mL}, 0.10 \mathrm{~mol}$ ) under $60 \mathrm{~min}$. The yellow solution was stirred for $5 \mathrm{~min}$ at $-84^{\circ} \mathrm{C}$ and $60 \mathrm{~min}$ at $-41^{\circ} \mathrm{C}$. The solution was cooled again to $-84^{\circ} \mathrm{C}$, and $p$-toluenesulfonyl bromide $(11.7 \mathrm{~g}, 0.050 \mathrm{~mol})$ was added. The mixture was stirred for 15 min at $-84^{\circ} \mathrm{C}$ and 60 min at $-41^{\circ} \mathrm{C}$. The solution was cooled to $-84^{\circ} \mathrm{C}$, and $p$-toluenesulfonyl bromide $(11.7 \mathrm{~g}, 0.05 \mathrm{~mol})$ was added. The mixture was stirred for $15 \mathrm{~min}$ and was then heated to ambient temperature on a room-tempered water bath. The reaction mixture was quenched with $\mathrm{H}_{2} \mathrm{O}(50 \mathrm{~mL})$, the phases were separated, and the aqueous phase was extracted with $\mathrm{Et}_{2} \mathrm{O}$ $(3 \times 20 \mathrm{~mL})$. The solvents from the combined organic phases were slowly removed on a rotary evaporator $\left(40{ }^{\circ} \mathrm{C}, 300 \mathrm{mbar}\right)$. The residue was dissolved in pentane $(50 \mathrm{~mL})$, washed with $\mathrm{H}_{2} \mathrm{O}$ $(10 \times 10 \mathrm{~mL})$, brine $(20 \mathrm{~mL})$, and dried over $\mathrm{Na}_{2} \mathrm{SO}_{4}$. The solvent was removed in vacuo $\left(40^{\circ} \mathrm{C}, 300 \mathrm{mbar}\right)$ and the product distilled ( $5 \times 10^{-2}$ mbar) using a short Vigreux column, collecting the main fraction at $29-31{ }^{\circ} \mathrm{C}$. This afforded 8 as a colorless liquid; yield $4.63 \mathrm{~g}$ (37\%). Analytical data were consistent with previous reports. ${ }^{14}$ The product was stored at $-20^{\circ} \mathrm{C}$ and should be used within a few weeks to avoid decomposition. 